\title{
Benchmarking Patenting Procedures: A Conceptual Model of the Procedure and Experiences of R\&D Scientists
}

\author{
Mary Mathew \\ Department of Management Studies \\ Indian Institute of Science \\ Bangalore 560012 INDIA
}

When economic policies liberalize the competitive efficiency of the National Patent System (NPS) is of immense significance. The stress on global leadership through technological breakthrough brings in the agenda for protection. With the 1991 economic liberalization, India is witnessing this paradigm shift. Steps towards building a patent culture is visible in Science and Technology laboratories such as the CSIR and IISc.

Much of R\&D Management literature focused on patent yield statistics. The emphasis on the NPS is not visible. A gestalt approach to understand a patent system provides knowledge that the NPS is a multi-component system, that is nation wide. The NPS is the system that socializes a national patent culture. A national patent culture is a scientific mindset that is conditioned to focus on global leadership for any scientific activity. In doing users seek protection within an efficient infrastructure that provides facilities, procedures and empowers more patents. The competitive efficiency of this system will help in enhancing the patent yield. Scientists at a diagnostic workshop conducted at the IISc, Bangalore, expressed the serious need to overhaul the patent system that exists. They shared their experiences during the stages of R\&D and also provided suggestions to improve the NPS.

The need to understand what other nations are doing and benchmark the patent process is imperative for the competitive efficiency of the NPS. The stages that R\&D personnel go through are eight in number. They are idea, R\&D activity, writing the technical specification, PO evaluation, clarifications, award of patent, the reward for patent and commercialization and publications. At each of these phases various components that are crucial in a NPS play a role. The components such as Patent Office, organizational factors, legal infrastructure, scientist, informational databases are illustrated in the paper. The processes and procedures of these components can be measured for efficiency. A framework of component processes for each stage developed based on the Indian procedures can be compared for efficiency across nations and benchmarked. This will provide an international standard of efficiency of the NPS. It will provide for more progressive and competitive patent worthy R\&D. 